\title{
Stress cardiomyopathy associated with vasodilator stress testing
}

\author{
William Morgan, MD, and Fadi Hage, MD, MASNC ${ }^{b}$ \\ a Internal Medicine, University of Alabama at Birmingham, Birmingham \\ b Division of Cardiovascular Disease, Birmingham Veterans Affairs Medical Center, University of \\ Alabama at Birmingham, Birmingham
}

Received Jan 24, 2020; accepted Jan 27, 2020

doi: $10.1007 / \mathrm{s} 12350-020-02064-\mathrm{w}$

\section{See related article, pp. 2421-2425}

Stress cardiomyopathy, also known as takotsubo cardiomyopathy, is a clinical syndrome that has been increasingly recognized over the past 30 years, and is manifested by temporary left ventricular (LV) systolic dysfunction that is not caused by an acute coronary syndrome. ${ }^{1}$ The classic description is hypokinesis of the LV apex with hyperkinesis of the base, also known as the "apical ballooning" pattern. This classical pattern is what lends the name takotsubo (Japanese term referring to an octopus trap which has a wide and rounded bottom with a narrow neck, thus resembling the LV shape on ventriculography in these patients) to the disease. Nevertheless, this pattern is not required for diagnosis and up to $25 \%$ of patients have other variants including midventricular hypokinesis, and the less common inverted form with basal hypokinesis. ${ }^{2}$ Awareness of these variants is important to accurately suspect and diagnose stress cardiomyopathy that may present atypically. Patients with stress cardiomyopathy are classically postmenopausal women, and frequently present with a clinical picture that is similar to an acute coronary syndrome including signs and symptoms such as substernal chest pain, dyspnea, ECG changes (ST elevation, $\mathrm{T}$ wave inversion, and prolonged QT interval), cardiac arrhythmias and positive cardiac biomarkers. ${ }^{3}$ The condition has been referred to as the "broken heart syndrome', as it is often, but not always, preceded by an

Reprint requests: William Morgan, MD, Internal Medicine, University of Alabama at Birmingham, Birmingham; williamsmorgan@ uabmc.edu

J Nucl Cardiol 2020;27:2426-8.

1071-3581/\$34.00

Copyright (C) 2020 American Society of Nuclear Cardiology. intense emotional or physical stress. Nevertheless, nearly a third of patients with stress cardiomyopathy may not have a clearly identifiable stressor. ${ }^{3}$ The Mayo Clinic diagnostic criteria require transient LV systolic dysfunction extending beyond a single coronary artery distribution, absence of obstructive coronary disease or angiographic evidence of acute plaque rupture, presence of new ECG abnormalities or cardiac biomarker elevation, and absence of pheochromocytoma or myocarditis. 1,4

Traditionally, stress cardiomyopathy is considered a transient and reversible disease with an ultimate recovery of LV systolic function which could occur quickly or could take weeks. In opposition to this benign outlook, it is now recognized that this entity is associated with a significant burden of complications including arrhythmia, cardiogenic shock, and death. Furthermore, the high recurrence rate (up to $20 \%$ at 10 years in some studies) suggests that the underlying dysfunction is not completely reversible. ${ }^{2}$ Consistent with this observation, Scally et al. recently reported persistence of heart failure symptoms, functional limitations and subclinical cardiac dysfunction by strain analysis at a median of 20 months after the index event despite normalization of $\mathrm{LV}$ ejection fraction. ${ }^{5}$

Imaging modalities most often used to assess for LV regional wall motion abnormalities associated with stress cardiomyopathy include echocardiography and invasive ventriculography that is obtained at the time of coronary artery evaluation. Alternatively, cardiac magnetic resonance imaging (CMR) can be used to further assess $\mathrm{LV}$ and right ventricular function. CMR can be helpful in differentiating stress cardiomyopathy from other diagnoses such as myocardial infarction or myocarditis by assessing for fibrosis, necrosis, and inflammation or edema. ${ }^{6,7}$ On CMR, late gadolinium enhancement (LGE) can sometimes be detected at a low threshold in stress cardiomyopathy, but is 
distinguishable from myocardial infarction which usually has intense LGE ( $>5$ standard deviations above the mean of remote myocardium) and myocarditis which has patchy LGE. ${ }^{6}$ Furthermore, the location of LGE can assist in the differential diagnosis as myocardial infarction often manifests with LGE that is either transmural or sub-endocardial, while in myocarditis the LGE is typically mid-wall or sub-epicardial. ${ }^{7}$ Finally, gated single photon emission computed tomography has also been used to identify patients with stress cardiomyopathy. ${ }^{8-10}$ This is clinically relevant since, as discussed above, many of these patients present with signs and symptoms that could be attributed to coronary artery disease and may, therefore, undergo non-invasive assessment of myocardial perfusion. It is, therefore, important for the imager to comment on regional wall motion abnormality and raise the suspicion for this clinical diagnosis in the appropriate setting so that further assessment can be performed.

The aetiology of stress cardiomyopathy is not well understood. Several mechanisms have been proposed including excessive sympathetic stimulation, microvascular dysfunction, metabolic dysfunction and hormonal effects (which may help explain the preponderance of this entity in postmenopausal women). It is postulated that catecholamines play a significant role in inducing stress cardiomyopathy either by microvascular spasm ${ }^{11}$ or direct cardiotoxicity. ${ }^{12}$ This mechanism is supported by imaging studies using ${ }^{123}$ I-metaiodobenzylguanidine (MIBG), a norepinephrine analogue, which demonstrate a decreased heart-to-mediastinal ratio and increased washout rate in these patients. ${ }^{13}$ Importantly, this sympathetic disruption persists for several months after the acute event. The presence of excess catecholamines can occur due to an extreme stressor leading to physiologic release of endogenous catecholamines, or can be iatrogenic in some cases. For example, some cases have been reported following the administration of intravenous epinephrine and dobutamine. ${ }^{14}$ The mechanism predisposing some individuals to develop cardiomyopathy in response to a stressor while others are unaffected by the same stressor is not entirely understood.

An interesting case report of stress cardiomyopathy induced by exercise treadmill testing demonstrated normal myocardial perfusion on imaging at the onset of the trigger for the syndrome. ${ }^{8}$ This report makes a strong argument for metabolic rather than vascular abnormality as the cause of contractile dysfunction. Positron emission tomography studies using F-18 labelled Fludeoxyglucose have demonstrated a metabolic abnormality in the affected area in the presence of normal or nearly normal perfusion-an imaging pattern that has been labelled as inverse perfusion/metabolism mismatch to contrast this with the imaging pattern seen in hibernating myocardium. ${ }^{15,16}$

In this issue of the Journal, Koester et al. report on a case of 72-year-old woman with known asthma who experienced stress cardiomyopathy following administration of adenosine and subsequent development of bronchospasm during cardiac stress testing. ${ }^{17}$ Unfortunately, myocardial perfusion imaging could not be performed in this patient since she underwent emergent cardiac catheterization. Adenosine is known to cause bronchospasm during stress testing and bronchospasm is one of the indications for reversal of vasodilator stress using intravenous aminophylline or other agents. ${ }^{18,19}$ This patient was appropriately treated with bronchodilators, oxygen, intravenous aminophylline, and intramuscular epinephrine. As the authors point out in the case study, there were multiple potential triggers of stress cardiomyopathy in this case including adenosineinduced bronchospasm, the administration of high doses of inhaled bronchodilators and intramuscular epinephrine. There have been several other case reports of stress cardiomyopathy attributed to bronchospasm in the context of pulmonary disease..$^{20,21}$ One case series described five patients that each presented with an acute COPD exacerbation, and were subsequently diagnosed with stress cardiomyopathy. ${ }^{21}$ The authors of the case series describe the novel term "bronchogenic stress cardiomyopathy,' and postulate that the cardiomyopathy could be due to the bronchospasm itself, or the high doses of inhaled bronchodilators (beta agonists and muscarinic antagonists) that the patients received. All five of the patients also received oral corticosteroids as a part of their treatment which provides yet another potential contributing factor to their development of stress cardiomyopathy.

It is important to note that activation of adenosine receptors, with adenosine or other agents such as regadenoson and dipyridamole, induces a sympathetic surge in the heart that is most manifested by an increase in the heart rate following the administration of these agents. $^{22-24}$ This is yet another mechanism for a possible trigger of stress cardiomyopathy in this patient and simultaneously provides supportive evidence of sympathetic stimulation as a root cause of the syndrome as discussed above. Indeed, there are other reported cases of stress cardiomyopathy associated with vasodilator stress tests in the absence of bronchospasm. ${ }^{25,26}$

Stress laboratories should be cognizant of potential complications of stress testing including the rare occurrence of stress cardiomyopathy that has been described with both exercise and vasodilator stress. 


\section{Disclosure}

Dr. Fadi Hage reports investigator initiated grant support from Astellas Pharma. Dr. William Morgan has no conflicts of interest to disclose.

\section{References}

1. Bybee KA, Kara T, Prasad A, Lerman A, Barsness GW, Wright RS, et al. Systematic review: Transient left ventricular apical ballooning: a syndrome that mimics ST-segment elevation myocardial infarction. Ann Intern Med 2004;141:858.

2. Medina de Chazal H, Del Buono MG, Keyser-Marcus L, Ma L, Moeller FG, Berrocal D, et al. Stress cardiomyopathy diagnosis and treatment: JACC State-of-the-Art Review. J Am Coll Cardiol 2018;72:1955-71.

3. Templin C, Ghadri JR, Diekmann J, Napp LC, Bataiosu DR, Jaguszewski M, et al. Clinical features and outcomes of Takotsubo (stress) cardiomyopathy. N Engl J Med 2015;373:929.

4. Prasad A, Lerman A, Rihal CS. Apical ballooning syndrome (Tako-Tsubo or stress cardiomyopathy): A mimic of acute myocardial infarction. Am Heart J 2008;155:3.

5. Scally C, Rudd A, Mezincescu A. Persistent long-term structural, functional, and metabolic changes after stress-induced (takotsubo) cardiomyopathy. Circulation 2018;137:1039-48.

6. Eitel I, von Knobelsdorff-Brenkenhoff F, Bernhardt P, Carbone I, Muellerleile K, Aldrovandi A, et al. Clinical characteristics and cardiovascular magnetic resonance findings in stress (takotsubo) cardiomyopathy. JAMA 2011;306:277-86.

7. Eitel I, Behrendt F, Schindler K, Kivelitz D, Gutberlet M, Schuler $\mathrm{G}$, et al. Differential diagnosis of suspected apical ballooning syndrome using contrast-enhanced magnetic resonance imaging. Eur Heart J 2008;29:2651.

8. Dorfman $\mathrm{T}$, Agel R, Allred J, Woodham R, Iskandrian AE. Takotsubo cardiomyopathy induced by treadmill exercise testing: An insight into the pathophysiology of transient left ventricular apical (or midventricular) ballooning in the absence of obstructive coronary artery disease. J Am Coll Cardiol 2007;49:1223-5.

9. Sabra MMM, Costa FS, de Azevedo JC, Mesquita CT, Verberne HJ. Myocardial perfusion scintigraphy during chest pain: An atypical presentation of takotsubo cardiomyopathy? J Nucl Cardiol 2019;26:674-6.

10. Albert CL, White KT, Cremer PC, Jaber WA. Stress for a stressed out heart: Classic cardiac PET findings in takotsubo cardiomyopathy. J Nucl Cardiol 2019;26:679-80.

11. Gianni M, Dentali F, Grandi AM, Sumner G, Hiralal R, Lonn E. Apical ballooning syndrome or takotsubo cardiomyopathy: A systematic review. Eur Heart J 2006;27:1523.

12. Nef H, Möllmann H, Kostin S, Troidl C, Voss S, Weber M, et al. Tako-Tsubo cardiomyopathy: Intraindividual structural analysis in the acute phase and after functional recovery. Eur Heart $\mathbf{J}$ 2007;28:2456.

13. Chen W, Dilsizian V. Exploring the pathophysiology of takotsubo cardiomyopathy. Curr Cardiol Rep 2017;19:53.

14. Abraham J, Mudd JO, Kapur NK, Klein K, Champion HC, Wittstein IS. Stress cardiomyopathy after intravenous administration of catecholamines and beta-receptor agonists. J Am Coll Cardiol 2009;53:1320.

15. Kobylecka M, Budnik M, Kochanowski J, Piatkowski R, Choinowski M, Fronczewska-Wienjawska K, et al. Takotsubo cardiomyopathy: FDG myocardial uptake pattern in fasting patients. Comparison of PET/CT, SPECT, and ECHO results. J Nucl Cardiol 2018;25:1260-70.

16. Feola M, Chauvie S, Rosso GL, Biggi A, Ribichini F, Bobbio M. Reversible impairment of coronary flow reserve in takotsubo cardiomyopathy: A myocardial PET study. J Nucl Cardiol 2008;15:811-7.

17. Koester C, Warner C, Hafiz AM, Martin R. A case of bronchospasm-induced takotsubo cardiomyopathy during adenosine stress testing. J Nucl Cardiol 2020. https://doi.org/10.1007/s1235 0-019-01996-2.

18. Andrikopoulou E, Hage FG. Adverse effects associated with regadenoson myocardial perfusion imaging. J Nucl Cardiol 2018;25:1724-31.

19. Abidov A, Dilsizian V, Doukky R, Duvall WL, Dyke C, Elliott $\mathrm{MD}$, et al. Aminophylline shortage and current recommendations for reversal of vasodilator stress: An ASNC information statement endorsed by SCMR. J Nucl Cardiol 2019;26:1007-14 Review.

20. Landefeld K, Saleh Q, Sander G. Stress cardiomyopathy in the setting of COPD exacerbation. J Invest Med High Impact Case Rep 2015;3:2324709615612847. https://doi.org/10.1177/ 2324709615612847.

21. Rajwani A, Adam Z, Hall JA. Bronchogenic stress cardiomyopathy: A case series. Cardiology 2015;130:106-11.

22. Hage FG, Dean P, Iqbal F, Heo J, Iskandrian AE. A blunted heart rate response to regadenoson is an independent prognostic indicator in patients undergoing myocardial perfusion imaging. J Nucl Cardiol 2011;18:1086-94.

23. Farris GR, Hage FG, Kumar V, Iskandrian AE. Indirect evidence of sympathetic stimulation by regadenoson. J Nucl Cardiol 2019;26:684-7.

24. Andrikopoulou E, Hage FG. Heart rate response to regadenoson: Making the case for its value in clinical practice. J Nucl Cardiol 2016;23:575-80.

25. Kalavakunta J, Zoltowska D, Agrawal Y, Gupta V. Regadenoson cardiac stress test-induced stress cardiomyopathy. BMJ Case Reports 2017. https://doi.org/10.1136/bcr-2017-221217.

26. Koh AS, Kok H, Chua T, Keng F. Takotsubo cardiomyopathy following dipyridamole pharmacologic stress. Ann Nucl Med 2010;24:497-500

Publisher's Note Springer Nature remains neutral with regard to jurisdictional claims in published maps and institutional affiliations. 